\section{Case Reports in Dermatology}

\title{
Delayed Diagnosis of Basal Cell Carcinoma of the Upper Lip: The Possible Role of Incidental Multinucleated Foreign Body Giant Cells
}

\author{
Joshua P. Hays C. Helen Malone Will E. Tausend Brandon P. Goodwin \\ Richard F. Wagner Jr. \\ Department of Dermatology, University of Texas Medical Branch, Galveston, TX, USA
}

\section{Keywords}

Basal cell carcinoma $\cdot$ Herpes $\cdot$ Herpes simplex $\cdot$ Tzanck smear $\cdot$ Valacyclovir $\cdot$ Acyclovir

\begin{abstract}
Herpes simplex and basal cell carcinoma (BCC) can have similar clinical presentations due to overlapping lesional morphology. We describe the unusual case of a BCC masquerading as herpes labialis due to a possible false-positive Tzanck smear. The confounding diagnosis led to a failed trial of valacyclovir and subsequent loss of the patient for 1 year before the lesion was biopsied and diagnosed as a BCC. This case report highlights the importance of careful inspection of herpetic lesions and that further investigation should be pursued if the etiology is uncertain or if the treatment is not yielding the expected results.
\end{abstract}

\section{Case Report}

In October 2015, a 44-year-old woman with no significant past medical history presented for evaluation of a persistent lesion on her upper lip. The area would frequently "flare," 
presenting as a crusted macule with occasional small erosions that would last for a few weeks and then heal. The woman had tried an over-the-counter topical cold sore medication but had not noticed much improvement. She denied any history of pain, tingling, or burning at the site. Oral valacyclovir was ordered for presumed herpes simplex virus (HSV), and she was instructed to return when flaring, if a diagnostic skin biopsy was desired, or if the symptoms did not improve within 6 weeks.

In December 2015, the patient returned for her 6-week follow-up. She was unable to buy valacyclovir due to cost and stated that she was unsure whether the cause was in fact HSV because she had never had cold sores. The lesion at this visit was visually similar to the original visit. A Tzanck smear performed from the lesion in standard fashion showed the presence of multinucleated giant cells, strengthening the diagnosis of herpes simplex. The patient was re-prescribed oral valacyclovir 1-g tablets to be taken daily and given a coupon to assist with the purchase.

One year later, in January 2017, the patient again returned for evaluation of the lesion. She stated that it had never healed, even with the use of valacyclovir, and so she returned for a biopsy. At this point, the lesion was a 7-mm erythematous crusted papule with slightly pearly rolled borders upon stretching (Fig. 1). A tangential biopsy was performed and demonstrated a basal cell carcinoma (BCC). The patient was then scheduled for Mohs surgery. Interestingly, multinucleated giant cells were noted on Mohs stage I adjacent to residual BCC (Fig. 2). The patient's timeline is demonstrated for clarity (Fig. 3).

\section{Discussion}

Differentiating herpes labialis lesions from BCC can be a clinical challenge due to overlap of classic lesion location and morphology. It is estimated that $49 \%$ of American women and $39 \%$ of American men between ages 0 and 49 are currently infected with HSV type 1 (HSV-1) [1]. Patients with reactivation of HSV-1 typically present with prodromal symptoms of pruritus and pain for a period of 6-53 $\mathrm{h}$ followed by the appearance of vesicles. In immunocompetent individuals, the median time from prodrome to resolution of vesicles is 5 days. The first-line treatment for herpes labialis is acyclovir or later-generation agents such as valacyclovir or penciclovir. These drugs require phosphorylation by a virally encoded thymidine kinase to become active. Once they are phosphorylated they can competitively inhibit viral DNA polymerase. Resistance to these drugs is through alterations of this phosphorylation pathway or changes to the viral DNA polymerase. HSV resistance to these drugs in immunocompetent hosts has remained stable at approximately $0.3 \%$ [2].

The incidence of BCC is imprecisely known in the US; however, it is estimated that over two million nonmelanoma skin cancers were treated in the US in 2006, the majority of which were BCCs [3]. The most important environmental cause of BCC is sun exposure, with incidence increasing with age [4]. Approximately $70 \%$ of BCCs occur on the face, owing to the increased sun exposure of this area. The most common subset of BCCs are nodular BCCs (60\% of cases); the patients typically present with a pink or flesh-colored papule having a pearly quality, with telangiectasia frequently seen within the papule [5]. BCCs have a wide variation of clinical presentations, so the diagnosis is usually confirmed with a tissue biopsy [6].

The Tzanck smear in this report was interpreted as demonstrating multinucleated giant cells by the clinical dermatologist, supporting the initial clinical diagnosis of herpes labialis. Herpes labialis typically will have cytologic changes of epithelial cells, including multinucle- 
ated giant cells that exhibit nuclear molding and margination of the chromatin. The Tzanck smear has been shown to have a relatively high sensitivity and specificity of 86 and $91 \%$, respectively, in the evaluation of herpetic lesions [7]. There is also evidence that it may be useful in initial screening of BCCs. Typically, the cytology will show clusters of deeply basophilic atypical cells [8]. One meta-analysis showed a sensitivity of $97 \%$ and a specificity of $86 \%$ for the detection of BCC by Tzanck smear [9].

The multinucleated giant cells reported in the patient's Tzanck smear were a confounding factor in this case and delayed the diagnosis and treatment of her BCC. It is interesting that multinucleated giant cells were noted on both her Tzanck smear and Mohs stage I. Multinucleated foreign body giant cells on a Tzanck smear could have been mistaken for the multinucleated giant cells seen in HSV infection. There are key differences between the cell architecture: multinucleated foreign body giant cells typically present with abundant cytoplasm and centrally located nuclei that are of uniform size and shape [10], while typical HSV multinucleated giant cells present with molding of the nuclei as they are crowded together, a peripheral margin of chromatin, and a ground-glass appearance of the nuclei [11]. An alternative explanation is that chronic inflammation due to valacyclovir-resistant HSV could provide increased risk for tumorigenesis of the site [12], although HSV has yet to be identified in this patient. A third alternative is that BCC on the Tzanck smear was misinterpreted as HSV multinucleated giant cells.

This case presentation of a BCC initially diagnosed as herpes labialis brings up several interesting issues. It is not clear whether the BCC appeared as a result of chronic inflammation associated with herpes labialis or whether the Tzanck smear was a false positive. A similar report in 1998 [13] misdiagnosed vulval BCC presenting as recurrent herpes genitalis. In that instance, the patient presented with a 4-year history of a recurrent blister that behaved similarly to herpes genitalis. She was treated with acyclovir but did not improve. Later, viral and bacterial cultures of the lesion were performed but were negative. An excisional biopsy was done and determined that the lesion was a BCC. These cases remind clinicians that herpetic lesions should be carefully investigated and biopsied if the etiology is uncertain or if treatment does not yield the expected results.

\section{Statement of Ethics}

Institutional review board approval was not required. Patient consent for publication of photos has been obtained.

\section{Disclosure Statement}

The authors declare that there is no conflict of interest regarding the publication of this article.

\section{References}

1 Looker KJ, Magaret AS, May MT, Turner KM, Vickerman P, Gottlieb SL, Newman LM: Global and regional estimates of prevalent and incident herpes simplex virus type 1 infections in 2012. PLoS One 2015;10: e0140765.

2 Bacon TH, Levin MJ, Leary JJ, Sarisky RT, Sutton D: Herpes simplex virus resistance to acyclovir and penciclovir after two decades of antiviral therapy. Clin Microbiol Rev 2003;16:114-128. 


\section{Case Reports in Dermatology}

Hays et al.: Delayed Diagnosis of Basal Cell Carcinoma of the Upper Lip: The Possible Role of Incidental Multinucleated Foreign Body Giant Cells

3 American Cancer Society: Cancer Facts and Figures 2010. Atlanta, American Cancer Society, 2010.

4 Hogan DJ, To T, Gran L, Wong D, Lane PR: Risk factors for basal cell carcinoma. Int J Dermatol 1989;28: 591-594.

-5 Haws AL, Rojano R, Tahan SR, Phung TL: Accuracy of biopsy sampling for subtyping basal cell carcinoma. J Am Acad Dermatol 2012;66:106-111.

-6 Telfer NR, Colver GB, Morton CA: Guidelines for the management of basal cell carcinoma. Br J Dermatol 2008;159:35-48.

7 Yaeen A, Ahmad QM, Farhana A, Shah P, Hassan I: Diagnostic value of Tzanck smear in various erosive, vesicular, and bullous skin lesions. Indian Dermatol Online J 2015;6:381-386.

8 Naraghi Z, Ghaninejad H, Akhyani M, Akbari D: Cytological diagnosis of cutaneous basal cell carcinoma. Acta Med Iran 2005;43:50-54.

9 Bakis S, Irwig L, Wood G, Wong D: Exfoliative cytology as a diagnostic test for basal cell carcinoma: a meta-analysis. Br J Dermatol 2004;150:829-836.

10 Durdu M, Baba M, Seçkin D: More experiences with the Tzanck smear test: cytologic findings in cutaneous granulomatous disorders. J Am Acad Dermatol 2009;61:441-450.

-11 Gupta G, Athanikar SB, Pai VV, Naveen KN: Giant cells in dermatology. Indian J Dermatol 2014;59: 481-484.

12 Coussens LM, Werb Z: Inflammation and cancer. Nature 2002;420:860-867.

13 Sherrard J, Bowen ML: Vulval carcinoma presenting as "recurrent herpes." Int J STD AIDS 1998;9:237.

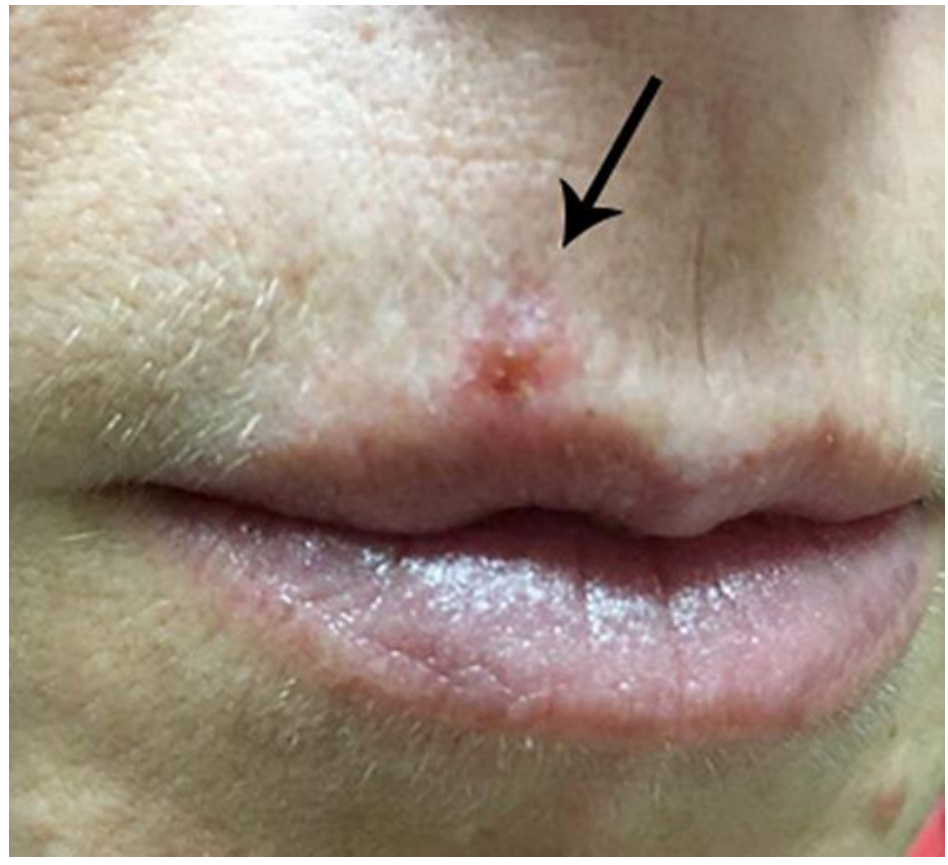

Fig. 1. Primary basal cell carcinoma of the right philtral column (arrow). 


\section{Case Reports in Dermatology}

\begin{tabular}{l|l}
\hline Case Rep Dermatol 2017;9:50-54 \\
\hline DOI: 10.1159/000477455 & $\begin{array}{l}\text { c } 2017 \text { The Author(s). Published by S. Karger AG, Basel } \\
\text { www.karger.com/cde }\end{array}$ \\
\hline
\end{tabular}

Hays et al.: Delayed Diagnosis of Basal Cell Carcinoma of the Upper Lip: The Possible Role of Incidental Multinucleated Foreign Body Giant Cells

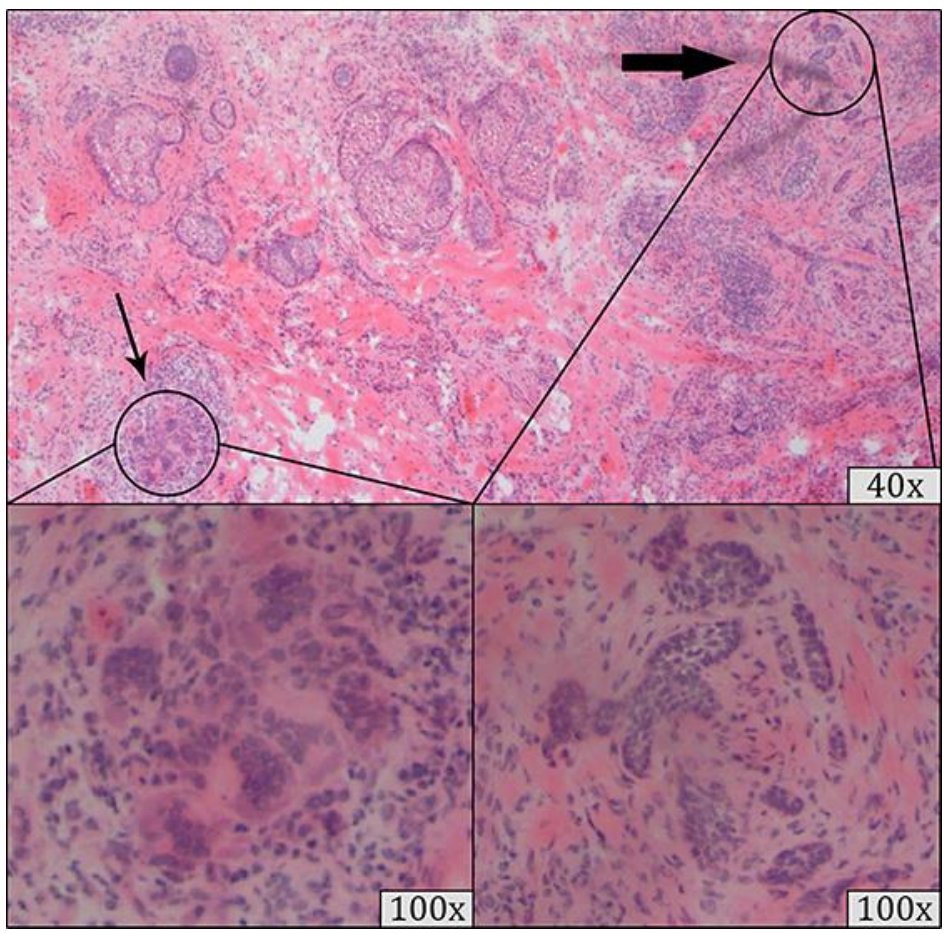

Fig. 2. Multinucleated foreign body giant cells (thin arrow) adjacent to residual basal cell carcinoma (thick arrow).
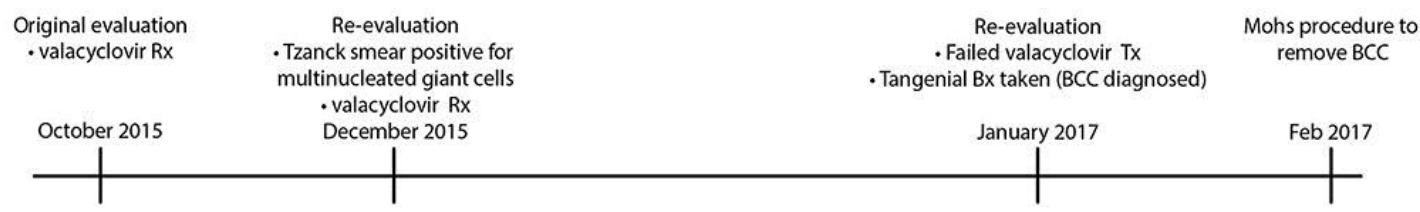

Fig. 3. Timeline of events. Rx, prescription; Tx, treatment; Bx, biopsy; BCC, basal cell carcinoma. 